\title{
A Future of Assessment Without Testing
}

\author{
SPECIAL ISSUE \\ Advancing Beyond Multiple Choice eAssessment
}

by Kristen DiCerbo

As with most aspects of life, assessment practices have been challenged by the events of 2020. The combination of the consequences of COVID-19 restrictions and the increased awareness and reckoning with systemic racism require the field to take a hard look at our assessment systems. The main function of assessment is to gather evidence by which to make inferences about what people know and can do. Over the past decade our digital capabilities have increased exponentially and offer potential to approach assessment differently. We now have digital learning environments that capture the actions of students as they engage in learning activity. It is possible to consider using this information as evidence such that assessment does not have to be a one-time event and we can have assessment without tests. There are some promising inroads in this direction, but also some lingering challenges remain. 


\title{
A Future of Assessment Without Testing
}

\author{
SPECIAL ISSUE \\ Advancing Beyond Multiple Choice eAssessment
}

by Kristen DiCerbo

\begin{abstract}
About the Author
Dr. Kristen DiCerbo is the chief learning officer at Khan Academy, a nonprofit dedicated to providing a free world-class education to anyone, anywhere. In this role, she is responsible for developing and implementing a research-based teaching and learning strategy for Khan Academy's offerings in order to improve student and teacher engagement and outcomes. Dr. DiCerbo's work has consistently been focused on embedding what we know from education research about how people learn into digital learning experiences. Prior to her role at Khan Academy, she was vice president of learning research and design at Pearson, served as a research scientist supporting teaching and learning in the Cisco Networking Academies, and worked as a school psychologist in an Arizona school district. She publishes and speaks to a variety of audiences about educational technology, learning, and learning science research. Kristen received her bachelor's degree from Hamilton College and master's degree and doctorate in Educational Psychology at Arizona State University.
\end{abstract}

DOI: $10.1145 / 3453989$ 